\title{
Elucidating protein-protein interactions using the HYDE scoring function
}

\author{
Eva Vennmann ${ }^{1 *}$, Nadine Schneider ${ }^{1}$, Gudrun Lange ${ }^{2}$, Matthias Rarey ${ }^{1}$ \\ From 9th German Conference on Chemoinformatics \\ Fulda, Germany. 10-12 November 2013
}

Protein-protein interactions take place in every aspect of life. The diversity of those interactions and their significant role in regulatory pathways account for the special interest in them. As shown in various diseases, protein-protein interactions can be deregulated and the cause of illness. Therefore, a better and more detailed understanding of protein-protein interactions is of great importance.

Protein-protein interactions can be classified according to their stability into permanent, long-lasting or transient, functionality-dependent complexes [1]. The latter ones are of special interest for using them to influence regulatory pathways. Deeper insights into protein-protein interactions can be achieved by comprehending the stability of protein-protein complexes and especially of the interface in all its details.

In our study we analyzed the stability of protein-protein interactions using the recently developed HYDE scoring function [2-4]. HYDE consistently describes hydrogen bonds, the hydrophobic effect and polar dehydration and has been proved successful in estimating protein-ligand binding affinities. In this way, HYDE enables to estimate the stability of protein-protein interactions as well as the energetical contribution of single amino acids e.g. to identify so called 'hotspot' residues.

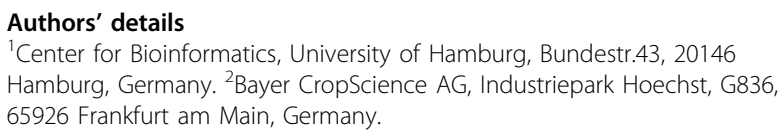

Published: 11 March 2014

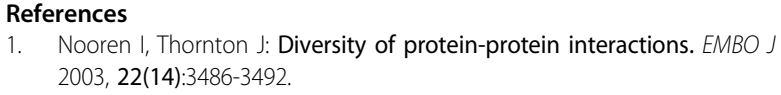

${ }^{1}$ Center for Bioinformatics, University of Hamburg, Bundestr.43, 20146 Hamburg, Germany

Full list of author information is available at the end of the article
2. Reulecke I, Lange G, Albrecht J, Klein R, Rarey M: Towards an Integrated Description of Hydrogen Bonding and Dehydration: Decreasing False Positives in Virtual Screening with the HYDE Scoring Function. ChemMedChem 2008, 3(6):885-897.

3. Schneider N, Klein R, Lange G, Rarey M: Nearly no Scoring Function without a Hansch-Analysis. Molecular Informatics 2012, 31(6-7):503-507.

4. Schneider N, Lange G, Hindle S, Klein R, Rarey M: A consistent description of HYdrogen bond and DEhydration energies in protein-ligand complexes: methods behind the HYDE scoring function. Journal of Computer-Aided Molecular Design 2013, 27(1):15-29.

doi:10.1186/1758-2946-6-S1-P36

Cite this article as: Vennmann et al:: Elucidating protein-protein interactions using the HYDE scoring function. Journal of Cheminformatics 2014 6(Suppl 1):P36. 